\section{OP37 THE ALBERTA ACCEPT STUDY: THE IMPACT OF A SYSTEM-WIDE ADVANCE CARE POLICY ON COMMUNICATION, CARE PLANNING AND DOCUMENTATION}

${ }^{1} S$ King, ${ }^{2} S$ Ghosh, ${ }^{2} \mathrm{M}$ Douglas, ${ }^{3} \mathrm{~A}$ Brisebois, ${ }^{3} \mathrm{~S}$ Hall, ${ }^{5} \mathrm{C}$ Brenneis, ${ }^{5} \mathrm{~W}$ Sia, ${ }^{4} \mathrm{D}$ Heyland, ${ }^{2} \mathrm{~K}$ Fassbender, ${ }^{2} \mathrm{~S}$ Davison, ${ }^{1} \mathrm{~J}$ Simon. ${ }^{1}$ University of Calgary, Calgary, Canada; ${ }^{2}$ University of Alberta, Edmonton, Canada; ${ }^{3}$ Alberta Health Services, EDMONTON, Canada; ${ }^{4}$ Queen's University, KINGSTON, Canada

\subsection{6/spcare-2019-ACPICONGRESSABS.37}

Background The ACCEPT survey (Audit of Communication, CarE Planning, and DocumenTation) evaluates the quality of Advance Care Planning (ACP) practice through patientreported experience measures and ACP documentation audit. We evaluated practice three years post system-wide policy for ACP implementation and patient awareness of their "Goals of Care Designation" (GCD) medical order.

Method Consecutive, consenting patients over 55 years with serious, chronic illness or age $>80$ years with any acute admission were prospectively enrolled from acute medical units in seven hospitals across Alberta, Canada. Research assistants administered the ACCEPT survey within 5 days of admission and reviewed participant charts for ACP and GCD documentation.

Results Of 502 patients (mean age 81 years, 53\% female) $93 \%$ had a GCD order in their chart but only $30 \%$ were aware of this. $33 \%$ reported having discussed none of the five key elements of goals of care conversations (patients' values and beliefs, prognosis, patients' fears and concerns, treatment preferences and prior ACP documentation or conversations) with a hospital clinician. Raw agreement between patients' expressed preferences for EOL care and documentation in patient charts was 56\% (concordance kappa $=0.273$ ). Multivariate regression analysis found that awareness of GCD order was associated with health region, patient frailty, quality of goals of care conversations in hospital and whether ACP conversations were considered important to the patient.

Conclusions Despite a system-wide policy, we found evidence of serious concerns about the quality of ACP and GCD practice. Intentional quality improvement interventions are likely needed to enhance practice and achieve patient-centred care.

\section{OP38 WITH WHICH PATIENTS DO PRIMARY CARE PROVIDERS START ACP CONVERSATIONS AND DOES THIS LEAD TO AN INCREASE IN ADVANCE DIRECTIVES?}

${ }^{1} \mathrm{~A}$ Van der Plas*, ${ }^{2} \mathrm{M}$ De Wit - Rijnierse, ${ }^{3} \mathrm{M}$ Eliel, ${ }^{1} \mathrm{~B}$ Onwuteaka - Philipsen. ${ }^{1} \mathrm{~V} U \mathrm{mc}$, Amsterdam, Netherlands; ${ }^{2} \mathrm{ZONH}$, Heerhugowaard, Netherlands; ${ }^{3}$ Westfriesgasthuis, Hoorn, Netherlands

\subsection{6/spcare-2019-ACPICONGRESSABS.38}

Background To improve uptake of ACP, primary care providers (PCP; general practitioners (GPs), community nurses, certified nursing assistants, practice nurses) were trained in ACP and received support during implementation.

Methods ACP was implemented in 10 GP-practices and 2 care homes. Before implementation a list was drawn up of all patients of 75 years or older in the GP practice or care home on 01-01-2017. On this list, PCP made a note of patients with whom they started a ACP conversation until 14 months after start of implementation. Also, questionnaires were sent to the patients before and 14 months after start of implementation. Now we present interim analyses, at the conference the final data will be available.

Results A total of 2292 older patients were enrolled with the GP practices or living in the nursing homes. Of those, 596 (26\%) received an offer of ACP and/or had an ACP conversation. The conversation was started more often with older patients (mean age 81 versus 83 years); female patients $(57 \%$ versus 64\%), and patients with at least one diagnosis $(88 \%$ versus 95\%). Questionnaires show an increase in advance directives $(31.1 \%$ versus $41.0 \%)$ after implementation, compared to before implementation.

Conclusions With a quarter of older patients an ACP conversation was started (ACP was offered and/or an ACP conversation was held). Advance directives are drawn up more often after implementation of ACP. Care providers make a selection in patients with whom they start the conversation.

\section{OP39 EVALUATION OF THE LIVING MATTERS ACP TRAINING COURSE FOR HEALTH PROFESSIONALS THROUGH A MULTI-CENTRE STUDY}

${ }^{1}$ EJ Koh, ${ }^{1} \mathrm{CC}$ Yu* ${ }^{1}{ }^{1} \mathrm{JA}$ Low, ${ }^{2} \mathrm{R}$ Ng. ${ }^{1}$ Geriatric Education and Research Institute, Singapore, Singapore; ${ }^{2}$ Tan Tock Seng Hospital, Singapore, Singapore

\subsection{6/spcare-2019-ACPICONGRESSABS.39}

Background The Living Matters ACP course trains healthcare professionals in Singapore to engage patients and families in ACP conversations. The assumption is that with more effective training, the knowledge, skills, attitude and confidence of participants in undertaking ACP conversations will improve.

Methods This mixed method study recruited a total of 223 healthcare professionals who attended the one-day course over a span of 1 year. Quantitative data were collected using pre and post-course questionnaires (immediate and 6-months) in domains on knowledge, skills, attitude, satisfaction, confidence and practice of the participants. Qualitative data from participants is currently being collected ( 3 to 12 months post-course) to determine their opinions and experiences on the training course and effects on practice.

Results Preliminary findings from the quantitative data suggest the course was efficacious in advancing participants' knowledge and self-reported skills and confidence. This was shown by the significant and practically large changes in matched $t$ test scores. Conversely, the course may have limited impact on attitudes since similar tests did not show changes of such magnitude and were largely trivial. Views suggest ACP conversations can be improved through means to enhance the emotional resilience of ACP facilitators and also means to navigate shared decision making and conflict resolution.

Conclusion Coupled with the qualitative data, current findings from this study can guide changes to the current ACP training in Singapore to make it more relevant and effective for healthcare providers. 